\title{
Mobilization and Micellar Solubilization of NAPL Contaminants in Aquifer Rocks
}

\author{
Gina Javanbakht and Lamia Goual* \\ Department of Chemical and Petroleum Engineering \\ University of Wyoming, 1000 E. University Ave., Laramie, WY 82071, USA \\ *E-mail: lgoual@uwyo.edu, Phone: 307-766-3278, Fax: 3-7-766-6777
}

\begin{abstract}
Surfactant-enhanced aquifer remediation is often performed to overcome the capillary forces that keep residual NAPL phases trapped within contaminated aquifers. The surfactant selection and displacement mechanism usually depend on the nature of NAPL constituents. For example, micellar solubilization is often used to cleanup DNAPLs from aquifers whereas mobilization is desirable in aquifers contaminated by LNAPLs. Although the majority of crude oils are LNAPLs, they often contain heavy organic macromolecules such as asphaltenes that are classified as DNAPLs. Asphaltenes contain surface-active components that tend to adsorb on rocks, altering their wettability. Previous studies revealed that surfactants that formed Winsor type III microemulsions could promote both mobilization and solubilization. However the extent by which these two mechanisms occur is still unclear, particularly in oil-contaminated aquifers.

In this study we investigated the remediation of oil-contaminated aquifers using an environmentally friendly surfactant such as $n$-Dodecyl $\beta$-D-maltoside. Focus was given on asphaltenes to better understand the mechanisms of surfactant cleanup. Through phase behavior, spontaneous imbibition, dynamic interfacial tension and contact angle measurements, we showed that microemulsions formed by this surfactant are able to mobilize bulk NAPL (containing 9 wt\% asphaltenes) in the porous rock and solubilize DNAPL (i.e., 4-6 wt\% adsorbed asphaltenes) from the rock surface. Spontaneous imbibition tests, in particular, indicated that the ratio of mobilized to solubilized NAPL is about 6:1. Furthermore, aging the cores in NAPL beyond 3 days allowed for more NAPL to be trapped in the large pores of the rock but did not alter the amount of asphaltenes adsorbed on the mineral surface.
\end{abstract}

Keywords: NAPL, Oil, Contamination, Aquifer, Surfactant, Remediation 


\section{INTRODUCTION}

The release of non-aqueous phase liquids (NAPLs) into the subsurface often poses a significant risk to the environment. The major sources of contamination are associated with accidental spills, inadequate disposal practices, and leakage from storage facilities. ${ }^{1}$ Although originating at ground surface, these contaminants can percolate through the vadose zone and find their way to moving groundwater aquifers, eventually reaching water wells, streams and lakes. ${ }^{1}$ Traditionally, NAPLs have been classified into chlorinated industrial solvents (e.g., perchloroethylene or PCE) and petroleum fluids (e.g., crude oil). ${ }^{2}$ Pumping groundwater for aboveground treatment is a standard remedy for groundwater contamination. However, remediation with pump-and-treat methods usually leaves a significant portion of residual NAPL phase trapped within the aquifer as capillary forces overcome viscous and buoyancy forces. ${ }^{3}$ This has prompted the development of alternative in situ technologies to provide enhanced remediation of NAPL source zones. ${ }^{4}$ One potentially viable remediation technology is surfactant flushing, also called surfactant-enhanced aquifer remediation (SEAR), in which a surfactant solution is pumped through a contaminated zone by introduction at an injection point and removal from an extraction point. ${ }^{3}$

Surfactants are delivered into the subsurface environment through the aqueous phase and can reduce the time and cost required for site remediation. ${ }^{5}$ They have a characteristic hydrophilic group (or polar head), which has a strong attraction for water or brine (i.e., salt water) together with a hydrophobic structural group (or aliphatic tail) that has a strong attraction for NAPL. The hydrophilic-lipophilic balance (HLB) number is a measure of the relative hydrophobicity of the surfactant. ${ }^{6}$ The most hydrophobic surfactants have an HLB number approaching zero, while the least hydrophobic ones have values reaching 40.7 NAPL contaminants such as oil tend to form oilin-water $(\mathrm{o} / \mathrm{w})$ microemulsions with hydrophilic surfactants (HLB $>>10)$ through the creation of direct micelles, or Winsor Type I system. On the other hand, water-in-oil (w/o) microemulsions can be generated with hydrophobic surfactants (HLB $<10$ ) through the formation of reverse or inverted micelles, or Winsor Type II system. Surfactants with an intermediate HLB number (i.e. close to 10) promote the formation of a separate bi-continuous middle-phase microemulsion, consisting of bilayer vesicles in equilibrium with aqueous and oil phases, or Winsor Type III system. $^{7}$ The type/concentration of surfactant, brine salinity, and temperature determine whether type I, II, or III system exists, and thus the NAPL recovery mechanism. 

micellar solubilization, NAPL is incorporated inside surfactant micelles and transported through brine (i.e., Winsor Type I system). It is therefore most effective above the critical micelle concentration (CMC) of the surfactant. ${ }^{8}$ The micellar incorporation step is based on the fact that micelles constantly dissociate and reform and that during reformation they can incorporate NAPL into their hydrophobic core. ${ }^{9}$ The design strategy of surfactant-enhanced NAPL solubilization is mainly based on the recovery of a contaminated aqueous phase. In the mobilization mechanism, the interfacial tension between NAPL and the brine is significantly reduced due to the formation of bilayer vesicles at the oil/water interface stabilized by surfactant molecules (i.e., Winsor Type III system). As a result, the capillary number increases and NAPL mobilization is facilitated. The design strategy in this case is based on the recovery of free phase NAPL. ${ }^{10}$ Previous work revealed that surfactant-enhanced mobilization is not appropriate with dense non-aqueous phase liquids (DNAPL) such as PCE where a lowering of interfacial tension may result in vertical mobilization of the contaminant deeper into the subsurface.11 Conversely, mobilization is desirable in aquifers contaminated by light non-aqueous phase liquids (LNAPL) such as crude oil.12 For example, surfactant flushing was very effective in mobilizing residual oil trapped in a well-controlled experimental site. ${ }^{13}$ The subsequent reduction in residual NAPL and increase of water relative permeability was optimized when the surfactant was applied during primary pumping rather than secondary recovery. ${ }^{10}$ Although increased efficiency with surfactant mixtures has been reported in the past, some challenges may arise due to micellar agglomeration ${ }^{13}$ or surfactant partitioning. ${ }^{14}$

While Winsor type III systems have usually been favored to mobilize NAPLs from contaminated aquifers, they may also promote contaminant solubilization. ${ }^{11}$ However the extend by which these two mechanisms occur is still unclear, particularly in oil-contaminated aquifers. Although the majority of crude oils are lighter than brine and thus considered as LNAPLs, they often contain heavy organic macromolecules (also called asphaltenes) that are denser than brine and thus classified as DNAPLs. Asphaltenes are a solubility class that is soluble in aromatics such as toluene but is insoluble in light alkanes such as heptane. ${ }^{15}$ Due to their polyaromatic structure and the presence of some heteroatoms (such as $\mathrm{O}, \mathrm{N}, \mathrm{S}$ ), they have a high propensity for self-association into nanoaggregates and clusters and can become colloidically unstable (i.e., flocculate) under certain conditions. The constituents of this heavy polydisperse phase are surface-active and tend to adsorb on rocks, altering their wettability. ${ }^{16}$ The extent of wettability alteration depends on their colloidal 
stability in NAPL and is enhanced with aging (i.e., contact time), ${ }^{17}$ especially at high temperatures. ${ }^{18}$

The objective of this study was to investigate the remediation of oil-contaminated aquifers using Winsor Type III surfactant systems. Several surfactant candidates were selected based on prior studies. We present here the results obtained with the most effective one: $n$-Dodecyl $\beta$-D-maltoside. This sugar-based surfactant displays unique interfacial behavior at solid/liquid interfaces and therefore it can have various applications such as aquifer remediation, flocculation/dispersion, wetting, and enhanced oil recovery. ${ }^{19}$

\section{MATERIALS AND METHODS}

\subsection{Materials}

\subsubsection{NAPL}

The NAPL phases used in this study consist of two medium crude oils. NAPL 1 is from Minnelusa formation in the Powder River Basin of Wyoming, and NAPL 2 is from Milne Point formation in Alaska. The properties of these NAPLs are provided in Table 1. Although their elemental compositions are fairly similar, NAPL 2 is slightly denser and more viscous than NAPL 1 . It also contains more asphaltenes precipitated by n-heptane, according to ASTM-D2007.20 The ratio between the total acid number (TAN) and the total base number (TBN) shows that NAPL 1 is more basic than NAPL 2. The aromaticity of NAPL 1 asphaltenes was determined at 300K using Bruker Advance DRX-600 NMR spectrometer. Details of the procedure can be found elsewhere.21,22

\subsubsection{Rock}

The aquifer rock samples were obtained from the Fountain formation located in east Colorado and Wyoming. This formation consists of a heterogeneous Pennsylvanian sedimentary rock consisting primarily of Conglomerate, Sandstone, or Arkose. Fountain sediments mostly formed from the Sherman Granite, which is an igneous formation. ${ }^{23}$ The rocks were sampled from surface outcrops of the Arkose layer, which were available near Owl Canyon in northeast Colorado. The permeability and porosity were measured for 10 different core samples using an automated permeameter and porosimeter (AP-608, Coretest System). This instrument uses a pressure decay technique to determine Klinkenberg-corrected permeabilities at confining pressures up to 9950 psi. The porosity of the rock samples was found to be in the range of $12-15 \%$ and their permeability varied between 2 and $5 \mathrm{mD}$. Scanning electron microscopy (SEM) images (see Figure 1) and energy 


\subsubsection{Surfactant}

The surfactant used in this study was $n$-Dodecyl $\beta$-D-maltoside (GC grade, >98\%, Sigma Aldrich). This nonionic, sugar-based, surfactant has many advantages such as biodegradability, low toxicity, environmental compatibility, low $\mathrm{CMC}$, and weak adsorption on minerals commonly found in subsurface formations. ${ }^{19}$ The structure of this surfactant can be found in Table 1. The large number 
of hydroxyl groups in the polar head indicates that this surfactant has a strong propensity for hydrogen bonding.

\subsection{Phase Behavior}

Phase behavior tests were performed in graduated glass tubes by preparing a brine solution $(0.2$ wt\% surfactant in brine) and mixing it with NAPLs at a volume ratio of 1:1. The surfactant concentration was ten times higher than the CMC (Section 3.3.1) to ensure that surfactant micelles form microemulsions with NAPL. The glass tubes were shaken for 1 hour with a speed of 300 strokes/minute and then rested for two days at $25{ }^{\circ} \mathrm{C}$ and atmospheric pressure to completely form a separate microemulsion phase (or rag layer) between of NAPL and the brine.

\subsection{High Resolution Transmission Electron Microscopy}

We used Tecnai TF20 S-Twin High Resolution Transmission Electron Microscope (HRTEM) from FEI. The microscope features a TIETZ F415MP 4k $\times 4 \mathrm{k}$ multiport CCD camera with a 4-port readout and $15 \mu \mathrm{m}$ pixel size. Two types of samples were prepared on silicon dioxide custom coated carbon TEM grids from SPI Supplies. The first sample contained surfactant micelles obtained by mixing 0.2 $\mathrm{wt} \%$ of surfactant in brine. The second sample consisted of $\mathrm{o} / \mathrm{w}$ microemulsions prepared by extracting a small amount of the rag layer between NAPL and brine (see Section 2.2). Because the rag layer phase was too thick to image under microscope, it was diluted 40 times in the same brine. All samples were imaged by the microscope at $200 \mathrm{kV}$ accelerating voltage under bright field illumination mode. Image $\mathrm{J}$ software was used for processing the images to measure the average size of the micelles and microemulsions particles. ${ }^{25}$

\subsection{Interfacial Tension and Contact Angle}

Dynamic interfacial tensions (IFT) between NAPL and brine and contact angles (CA) of NAPL/brine/mineral systems were measured with and without surfactant by rising/captive bubble tensiometry and a video-image digitization technique. The experimental set up includes a highresolution camera, a Hasteloy measurement cell and an automatic pump to provide stable flow rate during the measurement. This set-up was designed in a previous study by Saraji et al. ${ }^{26}$ All the measurements were conducted at ambient conditions. The density of fluids was measured at $20{ }^{\circ} \mathrm{C}$ using Anton Paar density meter. 

size of the needle was chosen based on the density difference and IFT of fluids in order to approach a Bond number close to unity. The needle diameter was varied between 1.6 and $2.1 \mathrm{~mm}$. The captured images were analyzed using the Axismetric Drop Shape Analysis (ADSA) by fitting the drop profile to Young-Laplace equation. ${ }^{27}$ This procedure has been used in previous studies. ${ }^{28}$ Note that the measurements of IFT between NAPL and surfactant solutions were not possible with the captive bubble method. Instead, we used a spinning drop tensiometer (SITE100, KRUSS), which provided more accurate values of IFT below $1 \mathrm{mN} / \mathrm{m}$. More details of this procedure can be found elsewhere.$^{29}$

During the CA tests, we used a needle with an outer diameter of $2.1 \mathrm{~mm}$ to inject/withdraw brine on/from the mineral surface with a flow rate of $0.002 \mathrm{~mL} / \mathrm{min}$. The brine bubble image was captured every 1 minute as it was growing or shrinking on the mineral surface. ImageJ software was used to determine CA from the captured images. Tests were performed on clean and NAPLcontaminated surfaces. The quartz surfaces (with a roughness of less than $0.5 \mathrm{~nm}$ ) were prewashed with diluted sulfuric acid and Nocromix mixture. The feldspar and calcite surfaces were polished in three steps with different sandpapers (sizes 120, 220 and 600 CAMI Grade), followed by three additional steps using monocrystalline diamonds (sizes $9 \mu \mathrm{m}, 3 \mu \mathrm{m}$ and $1 \mu \mathrm{m}$ ). All the contaminated mineral surfaces were prepared by immersing the clean minerals in brine for one week and then in NAPL for several days. Since the rock contained minor amounts of Muscovite (see Section 2.1.2), this mineral was not considered in this study.

\subsection{Core Flooding and Spontaneous Imbibition}

To perform spontaneous imbibition tests, small core samples with $38 \mathrm{~mm}$ diameter and $50.8 \mathrm{~mm}$ length were drilled from Arkose rock. The samples were polished and dried in an oven at $106{ }^{\circ} \mathrm{C}$ for 24 hours. The permeability and porosity of each sample were measured using the previously mentioned automated permeameter and porosimeter. For each set of tests, core samples with similar permeability and porosity were chosen. The samples were vacuumed at a pressure of $10^{-7}$ MPa for 24 hours. They were then saturated with brine for 24 hours to reach $100 \%$ brine saturation. The brine-saturated samples were placed inside the core holder shown in Figure 3 and NAPL 2 was injected with flow rates of $0.004,0.006$ and $0.008 \mathrm{ml} / \mathrm{min}$ until an initial brine saturation of about $50 \%$ was achieved after 3 days. NAPL 2 was selected here because of its 
relatively high asphaltene content. To investigate the effect of NAPL aging on the surfactant cleanup mechanism, we repeated this process then left the cores for 7 days in a tight container with NAPLwetted walls in order to eliminate any fluid evaporation. The total aging time in this case was 10 days instead of 3 days.

For the spontaneous imbibition tests, all core samples were placed in custom-made Amott imbibition cells filled with brine solutions (with and without $0.2 \mathrm{wt} \%$ surfactant). The volume of the recovered NAPL from the core samples was then recorded versus time for at least 150 hours until no more NAPL was produced. All the tests were performed at ambient temperature to better represent aquifer conditions.

\subsection{Asphaltene Content}

The concentration of asphaltenes in NAPL 2 produced from each spontaneous imbibition test was measured by dissolving NAPL 2 in heptane at a volume ratio of 1:40. The produced mixtures were shaken for 10 hours with a speed of 300 strokes/minute and asphaltenes were filtered under vacuum using a $0.02 \mu \mathrm{m}$ Whatman filter paper from Sigma Aldrich. The filtered asphaltenes were then washed with toluene and dried under vacuum.

\section{RESULTS AND DISCUSSION}

\subsection{Phase Behavior}

The phase behavior of $n$-Dodecyl $\beta$-D-maltoside was studied by mixing an equal volume of NAPL and brine in a graduated glass tube according to the procedure described in Section 2.2. Figure 4 reveals that the surfactant formed a middle-phase microemulsion phase with both NAPLs, leaving the brine phase very clear in color. Microemulsions were clearly visible with NAPL 1 since it is lighter and less dense than NAPL 2. This result indicates that the surfactant was able to form Winsor type III microemulsions between NAPL and brine, which promote the mobilization of NAPL. ${ }^{30}$

\subsection{HRTEM Imaging}

Figure 5(a) presents the HRTEM micrographs of surfactant micelles formed by mixing $0.2 \mathrm{wt} \%$ of $n$-Dodecyl $\beta$-D-maltoside in brine. Based on these images, the average diameter of surfactant micelles was found to be about $200 \mathrm{~nm}$. The images clearly show a core-shell structure composed of dark outer shells (i.e., surfactant heads) and grey inner cores (i.e., surfactant tails). These micelles 
are able to trap NAPL drops inside their cores and maintain them dispersed in the brine phase, as shown in Figure 5(b). We should note that in Winsor type III microemulsions, the dispersed NAPL/brine phases are in bilayer vesicle form. ${ }^{31}$ However, since we diluted the rag layer with brine to better capture images, these layers broke and formed stable o/w (i.e., Winsor type I) microemulsions with an average diameter of $800 \mathrm{~nm}$.

\subsection{Surface and Interfacial Tension}

The surface tension of brine was first measured versus surfactant concentration to estimate the CMC of the surfactant. Then a surfactant concentration above the CMC was selected to investigate the effect of surfactant on the IFT between NAPL 2 and brine.

\subsubsection{Effect of surfactant concentration on surface tension}

Figure 6 shows the effect of surfactant concentration on the surface tension of brine at ambient conditions. The surface tension decreased by increasing surfactant concentration due to the accumulation of surfactant molecules at the air/brine interface, thereby reducing its surface energy. This Figure shows a sharp decline in surface tension up to $0.02 \mathrm{wt} \%$, which corresponds to the critical micelle concentration (CMC) of the surfactant. The CMC represents the concentration at which surfactant molecules start to form micelles. Above this point, the surface tension remains constant regardless of surfactant concentration. The advantage of having a low CMC is that a lower amount of surfactant is needed to reduce the interfacial tension of NAPL/brine systems.

\subsubsection{Effect of surfactant on IFT}

The effect of surfactant on the interfacial tension between NAPL and brine was studied at $25{ }^{\circ} \mathrm{C}$ and atmospheric pressure. The surfactant concentration was ten times higher than the CMC (i.e., 0.2 $\mathrm{wt} \%$ ). For each measurement with the pendant drop method, the IFT varied in time for about four hours before it reached an equilibrium plateau. Conversely, measurements with the spinning drop method were relatively fast. Figure 7 reveals that the addition of surfactant to brine resulted in a very significant decrease in the IFT between NAPL and brine, by almost 99\% for NAPL 1 and 95\% for NAPL 2. At the NAPL/brine interface, the hydrophilic heads of the surfactant tend to remain in the aqueous phase while the hydrophobic tails stretch toward the NAPL phase. Therefore, a thin surfactant layer formed at the interface, which lead to an increase of the interfacial pressure and a reduction of the interfacial energy and IFT.32,33 The significant reduction of IFT with surfactant 
favors the formation of Winsor Type III microemulsions (see Figure 4) that promote the mobilization of NAPL from contaminated aquifers.

\subsection{Contact Angle}

The wettability of clean and contaminated minerals (feldspar, quartz, and calcite) was examined through dynamic contact angle measurements at ambient conditions with and without the presence of surfactant.

\subsubsection{Effect of NAPL contamination on minerals}

In order to establish the time required for aging clean mineral surfaces in NAPL, the minerals were first immersed in brine for 7 days (to reproduce aquifer conditions) before aging them in NAPL 1 for $1,4,7$, and 10 days. A drop of brine was then placed on each contaminated surface for dynamic contact angle measurements. Figure 8(a,b,c) displays a systematic increase in the contact angle with aging time on all three minerals. At such a high salinity $\left(1 \mathrm{M} \mathrm{CaCl}_{2}\right)$, the thin brine film between NAPL and mineral surface becomes unstable and collapses because of weak DLVO forces and more dominant electrostatic and van der Waals forces. ${ }^{34}$ The collapse of the brine film allows asphaltenes to adsorb onto the mineral surface and alter its wettability. ${ }^{35}$ Because adsorption is a kinetic process; the complete coverage of the surface requires a certain time. Our results indicate that a minimum of 3 days is needed to alter the wettability of these surfaces from strongly water-wet to weakly water-wet. Feldspar mineral experienced the highest wettability alteration with an increase in advancing contact angle from 51 to 81 degrees. On the other hand, calcite showed only a 15degree increase in contact angle. The same trend was also observed with NAPL 2-contaminated minerals, however the contact angles were smaller (Figure 8 (a)) since NAPL 2 is less basic than NAPL 1, thus there is less electrostatic repulsion between $\mathrm{Ca}^{2+}$ ions of brine and dissociated basic groups of NAPL.

\subsubsection{Effect of Surfactant on contaminated minerals}

Figure 9 shows that the addition of $0.2 \mathrm{wt} \%$ surfactant to brine could alter the wettability of NAPL 2-contaminated mineral surfaces from weakly-water wet back to strongly water-wet and also reduce the contact angle values by more than half for all three minerals. The angles are in fact slightly lower than those measured on original surfaces, possibly due to surfactant adsorption on the minerals, which may increase the affinity of brine molecules to the surface. ${ }^{36}$ Indeed, the contact angle formed by the surfactant solution is about 20 degrees, regardless of mineral type. The 
wettability reversal could be explained by the adsorption of surfactant molecules via their hydrophobic tails on the thin NAPL layer causing asphaltene molecules to detach and form Winsor Type I microemulsions similar to those shown in Figure 5.

\subsection{Spontaneous Imbibition}

Different sets of spontaneous imbibition tests were performed on Arkose core samples with similar permeabilities (2-3 $\mathrm{mD}$ ) and porosities (12-15\%) and containing $50 \%$ of initial brine saturation. We started the experiments by placing a core aged in NAPL 2 for 10 days in an Amott imbibition cell filled with brine. The volume of NAPL recovered from the core due to the spontaneous imbibition of brine was recorded (as a percentage of original NAPL volume) for at least 150 hours until no more NAPL was produced. Figure 10(a) reveals that the amount of NAPL mobilized by brine is about 13 vol\%. Furthermore, this NAPL has an asphaltene content of $3.2 \mathrm{wt} \%$, showing that about $6 \mathrm{wt} \%$ of asphaltene in the originally injected NAPL remained adsorbed on the rock surface (Figure 11). This is due to the fact that brine imbibes into smaller pores (with larger surface area to volume ratio) rather than larger pores containing bulk NAPL (with $9 \mathrm{wt} \%$ asphaltene). The large surface area in smaller pores promotes the adsorption of asphaltenes that cannot be solubilized by brine alone.

In parallel, anther core aged in NAPL 2 for 10 days was placed in a separate Amott imbibition cell filled with the surfactant solution ( $0.2 \mathrm{wt} \%$ surfactant in brine) and the volume of NAPL recovered from the core was recorded versus time. Because of its lower interfacial tension with NAPL (Figure 7), the surfactant solution can invade small pores as well as larger pores. Figure 10(a) shows that the surfactant solution could remove a total of 22 vol\% of NAPL from the core, 9 vol\% more than without surfactant. The produced NAPL contained $15.2 \mathrm{wt} \%$ asphaltenes (Figure 11), suggesting that it was produced by two different mechanisms. One is likely due to the mobilization of bulk NAPL phase in the small and large pores (with $9 \mathrm{wt} \%$ asphaltenes), and another one is due to the micellar solubilization of NAPL, which involves the desorption of $6 \mathrm{wt} \%$ asphaltenes from the surface of the pores.

Figure 10(a) displays a distinct jump in the production curve, corresponding to the time at which solubilization is started, in addition to the mobilization mechanism. Assuming that the mobilization curve with surfactant has the same shape as the one without surfactant, the amounts of additional mobilization and solubilization by surfactant could be estimated to be 6 vol\% and 3 vol\%, respectively. In the case of brine imbibition there is no jump in the production curve, showing again 
that only the surfactant solution can dissolve and produce the adsorbed asphaltene. This means that the ratio of mobilized to solubilized NAPL is about $6: 1$, whereas with no surfactant, all produced NAPL was due to mobilization.

To investigate the effect of NAPL aging on the surfactant cleanup mechanism, we considered another set of cores aged in NAPL for 3 days according to the procedure described in Section 2.5 (without aging for the extra 7 days). The imbibition tests with brine and surfactant solution were again performed and the produced NAPL was analyzed for asphaltene content. These results show that in the case of brine imbibition, the volume of mobilized NAPL is about the same as the one from 10 day-aged cores, however it was achieved at a higher rate (Figure 10(b)). Figure 11 indicates that the asphaltene content in produced NAPL from 3 day aging and 10 day aging is very similar (within the experimental error). The surfactant solution could remove a total of $20 \mathrm{vol} \%$ of NAPL from the core, 5 vol\% more than without surfactant. The produced NAPL contained about 13 wt $\%$ asphaltenes (Figure 11), showing again the effectiveness of surfactant in desorbing asphaltenes from the core sample. The ratio of mobilized to solubilized NAPL in this case was slightly lower than 6:1.

The production curve of NAPL with surfactant imbibition still shows a jump. This jump accounts for $3 \mathrm{vol} \%$ more production due to solubilization, which is the same as the case of 10 day-aged core samples. Contact angle measurements versus aging time on different mineral surfaces (Figure 8) indicated that there was no change in wettability after 3 days, meaning that the amount of adsorbed asphaltenes was constant. This observation, along with the fact that it took 3 days for the cores to reach to $50 \%$ brine saturation by NAPL injection, explains the similarity of the NAPL production due to micellar solubilization ( 3 vol\%) in the 10 and 3 days aged core samples. In other words, the amount of adsorbed asphaltene remained constant after the third day.

Figure 12 illustrates the mobilization and micellar solubilization mechanisms observed in this study. Fast mobilization of LNAPL (through formation of Winsor Type III microemulsions) occurs first followed by the slow micellar solubilization of DNAPL (i.e., asphaltenes). The wettability reversal is due to the adsorption of surfactant molecules via their hydrophobic tails on the thin asphaltene layer causing it to detach and form Winsor Type I microemulsions. Mobilization here was the dominant mechanism because asphaltene nanoaggregates were colloidically stable in NAPL and their adsorption on mineral surfaces reached saturation relatively fast. However there are 
situations where asphaltene aggregates may become unstable and flocculate (for instance, due to incompatible fluid mixing), leading to much larger amounts of DNAPL deposited on mineral surfaces that may hinder NAPL displacement in porous media. In this case, micellar solubilization may become the dominant mechanism. Therefore, the selection of surfactants and the effectiveness of aquifer remediation strategies depend on the colloidal stability of asphaltenes in the NAPL phase.

\section{CONCLUSIONS}

Phase behavior, spontaneous imbibition, dynamic interfacial tension and contact angle measurements were performed to investigate the impact of $n$-Dodecyl $\beta$-D-maltoside on NAPL (i.e., oil) removal from contaminated aquifer rocks. Phase behavior and IFT tests revealed that the surfactant was able to form Winsor type III microemulsions with NAPL and brine that are characterized by a very low IFT. These microemulsions were responsible for the mobilization of bulk NAPL (containing $9 \mathrm{wt} \%$ asphaltenes) in the porous rock. Dynamic contact angle tests showed that the surfactant could also remove DNAPL constituents of oil (i.e., 4-6 wt\% adsorbed asphaltenes) that altered its wettability from strongly to weakly water-wet. The mechanism of DNAPL desorption is believed to occur through solubilization of DNAPL constituents inside surfactant micelles and formation of Winsor type I microemulsions. Spontaneous imbibition tests indicated that mobilization occurred to a grater extent than micellar solubilization. The ratio of mobilized to solubilized NAPL was estimated to be 6:1. The prolonged aging time of the cores (beyond 3 days) allowed for more NAPL to be trapped in the large pores of the rock but did not impact the amount of asphaltenes adsorbed on the mineral surface. This is because asphaltenes were colloidically stable in NAPL and their adsorption on mineral surfaces reached saturation within 3 days.

\section{ACKNOWLEDGEMENTS}

The authors would like to thank the National Science Foundation (Career Award \#1351296) and Hess Corporation for financial support. The authors are also grateful to Dr. Erwin Sabio for HRTEM imaging, Dr. Nick Jones and Dr. Steve Fryberger for their help in collecting the rock samples, and Dr. Amir Hossein Alizadeh for his assistance with the core flooding experiments.

\section{REFERENCES}

(1) Bear, J. Dynamics of fluids in porous media: New York, Am. 65-80, 1972.

(2) US Environmental Protection Agency, 2011. Available at 
http://water.epa.gov/type/groundwater/uic/class2/hydraulicfracturing/upload/hf study pl an 110211 final 508.pdf

(3) Naval Facilities Engineering Command, Surfactant-Enhanced Aquifer Remediation (SEAR) Design Manual, NFESC Technical Report TR-2206 ENV, Washington DC, April 2002.

(4) Jawitz, J. W.; Annable, M. D.; Rao, P. S. C.; Rhue, R. D. Evaluation of Remediation Performance and Cost for Field-Scale Single-Phase Microemulsion (SPME) Flushing. Journal of Environmental Science and Health, Part A 2001, 36 (8), 1437-1450.

(5) Istok, J. D.; Field, J. In Situ, Field Scale Evaluation of Surfactant Enhanced DNAPL Recovery Using a Single-Well, Push-Pull Test; EMSP-55196-1999; Oregon State University, Corvallis, Oregon, 1999.

(6) Griffin, W. C. Calculation of HLB Values of Non-Ionic Surfactants. Am. Perfumer Essent. Oil Rev. 1955, 65, 26-29.

(7) Israelachvili, J. N. Intermolecular and Surface Forces: Revised Third Edition, Academic Press, 2011.

(8) Schramm, L. L. Fundamentals and Applications in the Petroleum Industry, Cambridge University Press, November 2010.

(9) Zhong, L.; Mayer, A. S.; Pope, G. A. The Effects of Surfactant Formulation on Nonequilibrium NAPL Solubilization. Journal of Contaminant Hydrology 2003, 60 (1-2), 55-75.

(10) Chevalier, L. R. Surfactant Dissolution and Mobilization of LNAPL Contaminants in Aquifers. Environ Monit Assess 2003, 84 (1-2), 19-33.

(11) Loewe, D.; Oubre, C.; Ward, C. Surfactants and Cosolvents for NAPL Remediation. A Technology Practice Manual 2000.

(12) Kovar, K.; Herbert, M. GQ’98; International Association of Hydrological Sciences, 1998.

(13) Bettahar, M.; Ducreux, J.; Schäfer, G.; van Dorpe, F. Surfactant Enhanced In Situ Remediation of LNAPL Contaminated Aquifers: Large Scale Studies on a Controlled Experimental Site. Transport in Porous Media 1999, 37 (3), 255-276.

(14) Cowell, M. A.; Kibbey, T. C. G.; Zimmerman, J. B.; Hayes, K. F. Partitioning of Ethoxylated Nonionic Surfactants in Water/NAPL Systems: Effects of Surfactant and NAPL Properties. Environ. Sci. Technol. 2000, 34 (8), 1583-1588.

(15) Mitchell, D. L.; Speight, J. G. The Solubility of Asphaltenes in Hydrocarbon Solvents. Fuel 1973, $52(2), 149-152$. 
(16) Amin, J. S.; E.Nikooee; Ghatee, M. H.; Ayatollahi, S.; Alamdari, A.; Sedghamiz, T. Investigating the Effect of Different Asphaltene Structures on Surface Topography and Wettability Alteration. Applied Surface Science 2011, 257 (20), 8341-8349.

(17) Buckley, J. S. Wetting Alteration of Solid Surfaces by Crude Oils and their Asphaltenes, Oil \& Gas Science and Technology - Rev. IFP 53 1998, (3), 303-312.

(18) Al-Aulaqi, T.; Grattoni, C.; Fisher, Q.; Musina, Z.; Al-Hinai, S. Effect of Temperature, Oil Asphaltene Content, and Water Salinity on Wettability Alteration; Society of Petroleum Engineers, paper 149071-MS presented at the SPE/DGS Saudi Arabia Section Technical Symposium and Exhibition, 15-18 May, Al-Khobar, Saudi Arabia, 2011.

(19) Zhang, L.; Somasundaran, P.; Maltesh, C. Adsorption of n-Dodecyl-B-D-Maltoside on Solids. Journal of Colloid and Interface Science 1997, 191 (1), 202-208.

(20) American Society for Testing and Material, Annual Book of ASTM Standards, ASTM D2007, Philadelphia, PA, 1991.

(21) Saraji, S.; Goual, L.; Piri, M. Adsorption of Asphaltenes in Porous Media under Flow Conditions. Energy Fuels 2010, 24 (11), 6009-6017.

(22) Sedghi, M.; Goual, L. Role of Resins on Asphaltene Stability. Energy Fuels 2010,24(4), 22752280.

(23) Howard, J. D. Patterns of Sediment Dispersal in the Fountain Formation of Colorado. The Mountain Geologist 1966, 3 (4), 147-153.

(24) Mazor, E. Understanding Groundwater Systems of the Southern Laramie Basin, Albany County, Wyoming through Applied Chemical and Physical Data, Report WWWRC-90-19, Wyoming Water Research Center, 1990.

(25) Vega, C.; de Miguel, E. Surface Tension of the Most Popular Models of Water by Using the TestArea Simulation Method. J. Chem. Phys. 2007, 126, 154707-10.

(26) Saraji, S.; Goual, L.; Piri, M.; Plancher, H. Wettability of Supercritical Carbon Dioxide/Water/Quartz Systems: Simultaneous Measurement of Contact Angle and Interfacial Tension at Reservoir Conditions. Langmuir 2013, 29 (23), 6856-6866.

(27) Neumann, A. W.; David, R.; Zuo, Y. Applied Surface Thermodynamics, Second Edition, CRC Press, 2011.

(28) Saraji, S.; Piri, M.; Goual, L. The Effects of SO2 Contamination, Brine Salinity, Pressure, and Temperature on Dynamic Contact Angles and Interfacial Tension of Supercritical C02/brine/quartz Systems. International Journal of Greenhouse Gas Control 2014, 28, 147155. 
(29) Vonnegut, B. Rotating Bubble Method for the Determination of Surface and Interfacial Tensions. Review of Scientific Instruments 1942, 13 (1), 6-9.

(30) Rosen, M. J.; Kunjappu, J. T. Surfactants and Interfacial Phenomena; John Wiley \& Sons, 2012.

(31) Fanun, M. Microemulsions: Properties and Applications; CRC Press, 2008.

(32) Al-Rossies, A. A. S.; Al-Anazi, B. D.; Paiaman, A. M. Effect of pH-Values on the Contact Angle and Interfacial Tension. NAFTA 2010, 61 (4), 181-186.

(33) Buckley, J. S. Chemistry of the Crude Oil/Brine Interface. Proc. 3rd International Symposium on Evaluation of Reservoir Wettability and Its Effect on Oil Recovery. 1994.

(34) Buckley, J. S.; Liu, Y.; Monsterleet, S. Mechanisms of Wetting Alteration by Crude Oils. SPE Journal 1998, 3 (01), 54-61.

(35) Saraji, S.; Goual, L.; Piri, M. Adsorption of asphaltenes in porous media under flow conditions. Energy \& Fuels 2010, 24, 6009-6017.

(36) Chaudhuri, R. G.; Paria, S. Effect of Electrolytes on Wettability of Glass Surface Using Anionic and Cationic Surfactant Solutions. Journal of Colloid and Interface Science 2014, 413, 24-30. 
Table 1. Properties of NAPLs and Surfactant

\begin{tabular}{|c|c|c|}
\hline \multicolumn{3}{|c|}{ NAPLs } \\
\hline & $\begin{array}{l}\stackrel{\text { NAPL 1 }}{\text { Minnelusa oil }} \\
\underline{\underline{n}}\end{array}$ & $\begin{array}{l}\text { NAPL } 2 \\
\text { Milne Point oil }\end{array}$ \\
\hline$\rho^{20 C}(\mathrm{~g} / \mathrm{mL})$ & 0.871 & 0.9214 \\
\hline Reflective Index at $20^{\circ} \mathrm{C}$ & 1.483 & 1.5222 \\
\hline Viscosity (mPa.s) & 11.833 & 112.0 \\
\hline $\mathrm{C}(\%)$ & 86.69 & 85.07 \\
\hline $\mathrm{H}(\%)$ & 6.65 & 7.75 \\
\hline $\mathrm{N}(\%)$ & 0.83 & 1.09 \\
\hline $0(\%)$ & 1.36 & 1.61 \\
\hline $\mathrm{S}(\%)$ & 4.51 & 4.63 \\
\hline $\mathrm{H} / \mathrm{C}$ & 0.92 & 1.1 \\
\hline Asphaltenes (wt\%) & 3.29 & 9.03 \\
\hline TAN (mg of $\mathrm{KOH} / \mathrm{g}$ ) & 0.110 & 1.69 \\
\hline TBN (mg of $\mathrm{KOH} / \mathrm{g}$ ) & 0.955 & 2.25 \\
\hline TBN/TAN & 8.6 & 1.33 \\
\hline Aromaticity (\%) & 63 & - \\
\hline \multicolumn{3}{|c|}{ Surfactant (n-Dodecyl $\beta$-D-Maltoside) } \\
\hline Structure & $\mathrm{OH} \mathrm{OH}$ & $\left.\mathrm{I}_{2}\right)_{10} \mathrm{CH}_{3}$ \\
\hline $\begin{array}{l}\text { Formula } \\
\text { Molecular weight }(\mathrm{g} / \mathrm{mol}) \\
\text { HLB }\end{array}$ & & \\
\hline
\end{tabular}

Table 2. Concentration of cations in the aquifer of Fountain formation

\begin{tabular}{|cc|}
\hline Cation & $\begin{array}{c}\text { Concentration } \\
\text { (ppm) }\end{array}$ \\
\hline $\mathrm{Al}^{+3}$ & 0.116 \\
$\mathrm{~B}^{+3}$ & 3.031 \\
$\mathrm{Ca}^{+}$ & $\mathbf{2 0 . 4 3}$ \\
$\mathrm{Cu}^{+2}$ & 0.022 \\
$\mathrm{Fe}^{+2}$ & 0.078 \\
$\mathrm{~K}^{+1}$ & 2.868 \\
$\mathrm{Mg}^{+2}$ & 0.445 \\
$\mathrm{Mn}^{+2}$ & 0.007 \\
$\mathrm{Na}^{+1}$ & 3.609 \\
\hline
\end{tabular}




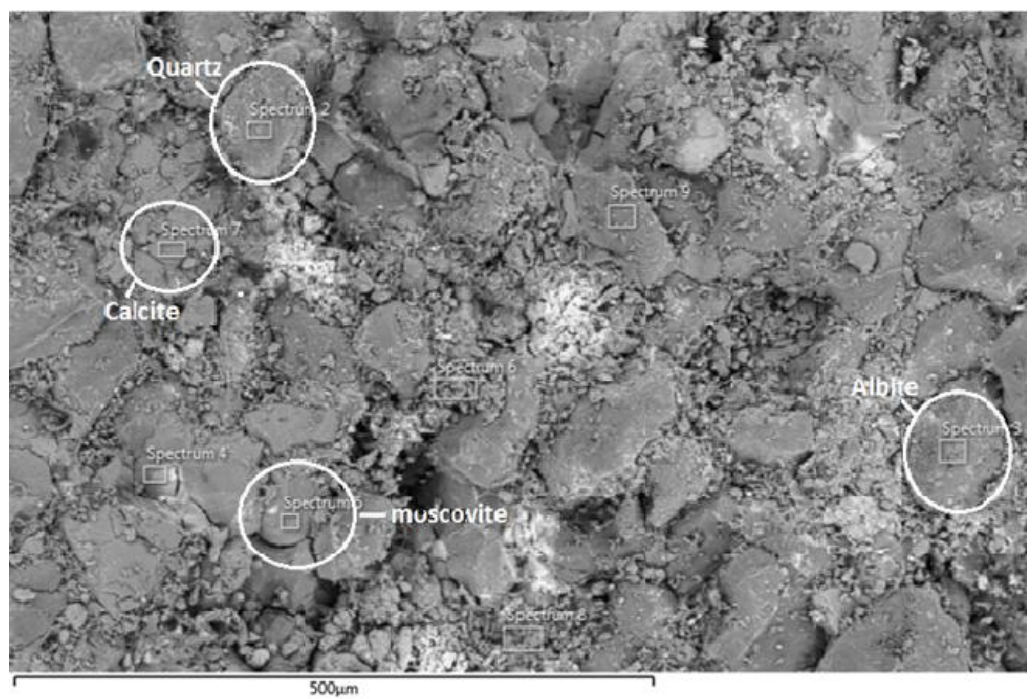

Figure 1. SEM image of Arkose rock

(a)
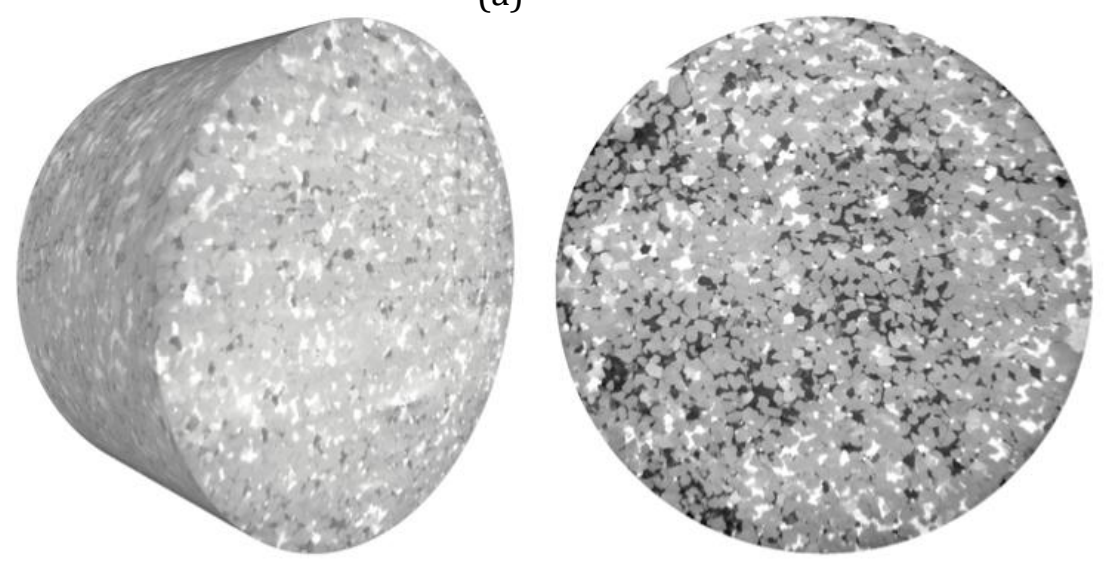

(b)
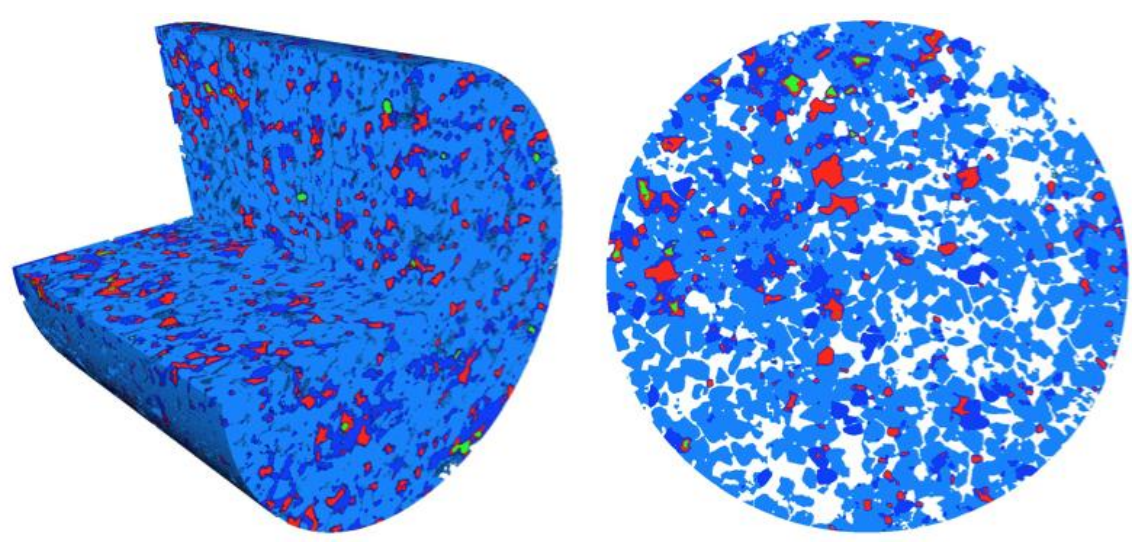

Figure 2. (a) High-resolution micro-CT images of Arkose rock, (b) segmented images: pores in white, feldspar in light blue, quartz in dark blue, calcite in red, and muscovite in green 


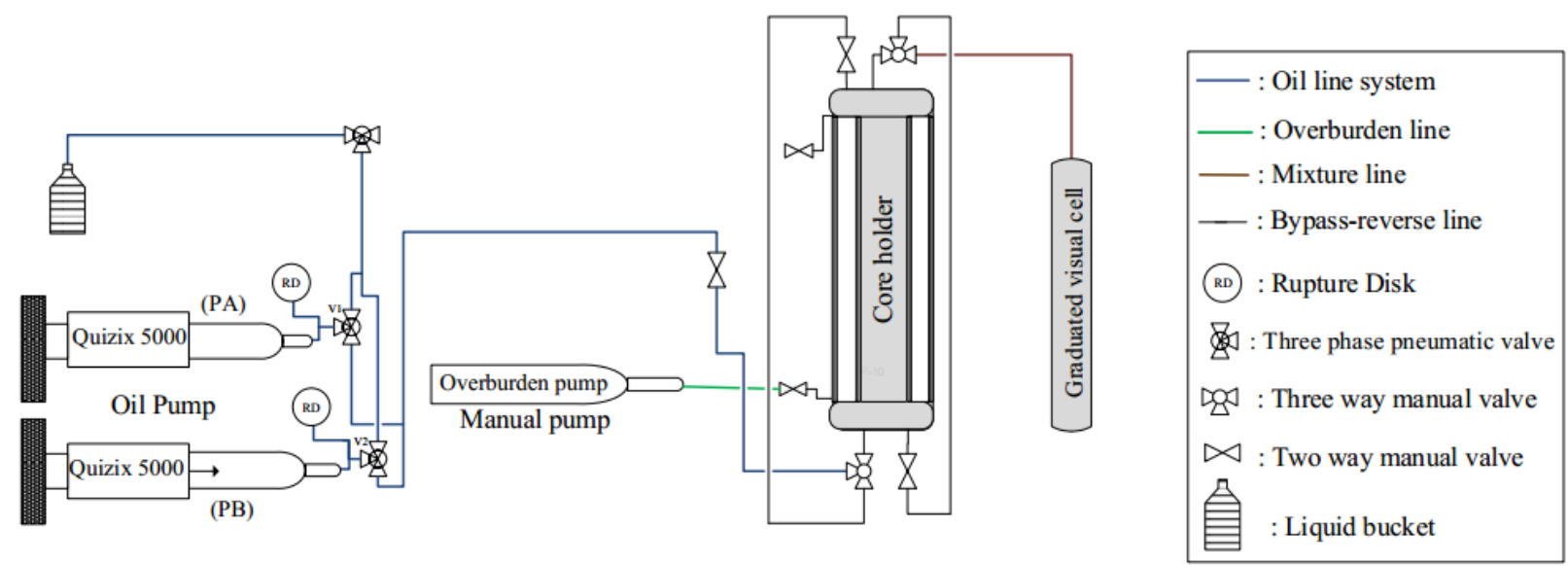

Figure 3. Schematic of the core flooding system used to obtain an initial water saturation of 50 $\mathrm{wt} \%$ in Arkose core samples

(a) NAPL 1

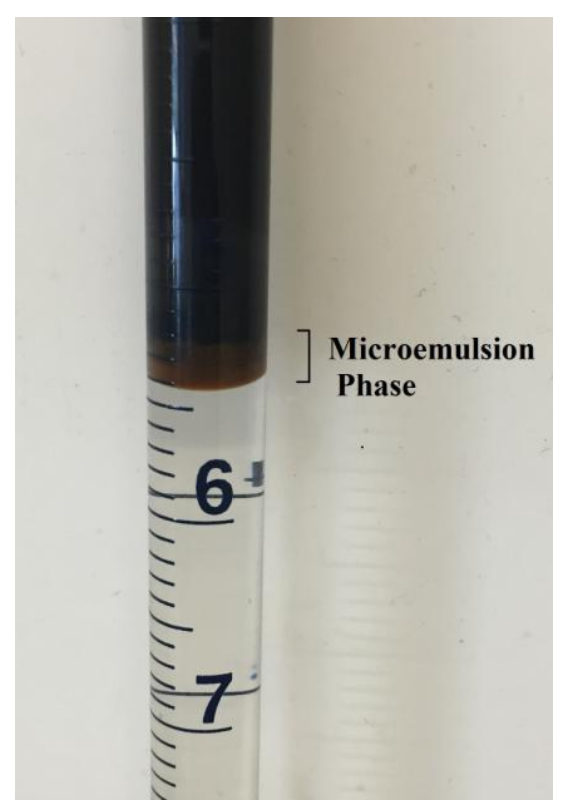

(b) NAPL 2

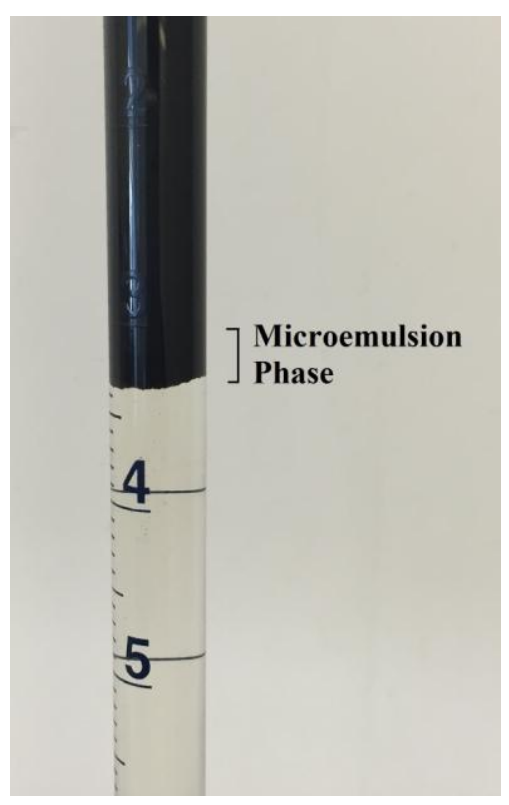

Figure 4. Winsor type III microemulsion phase between top NAPL (oil) and bottom brine solution (with 0.2 wt $\%$ surfactant) 
(a) Surfactant micelles
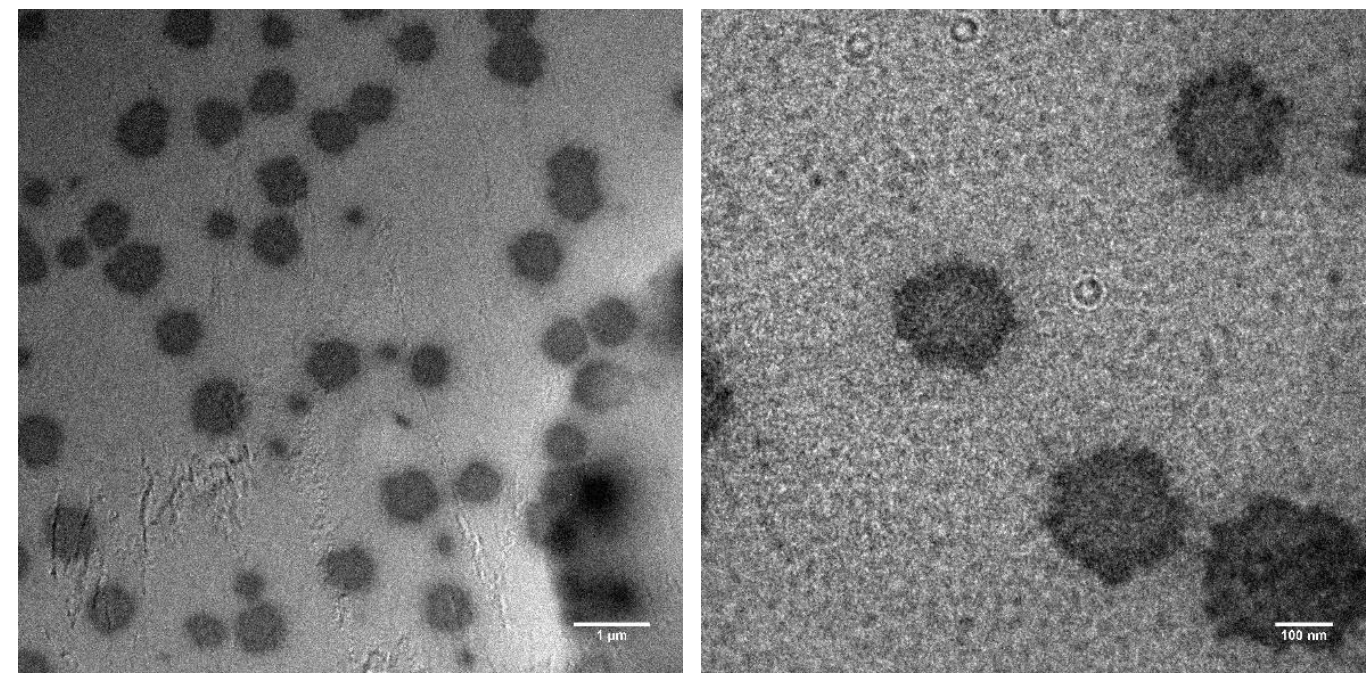

(b) 0/W microemulsions
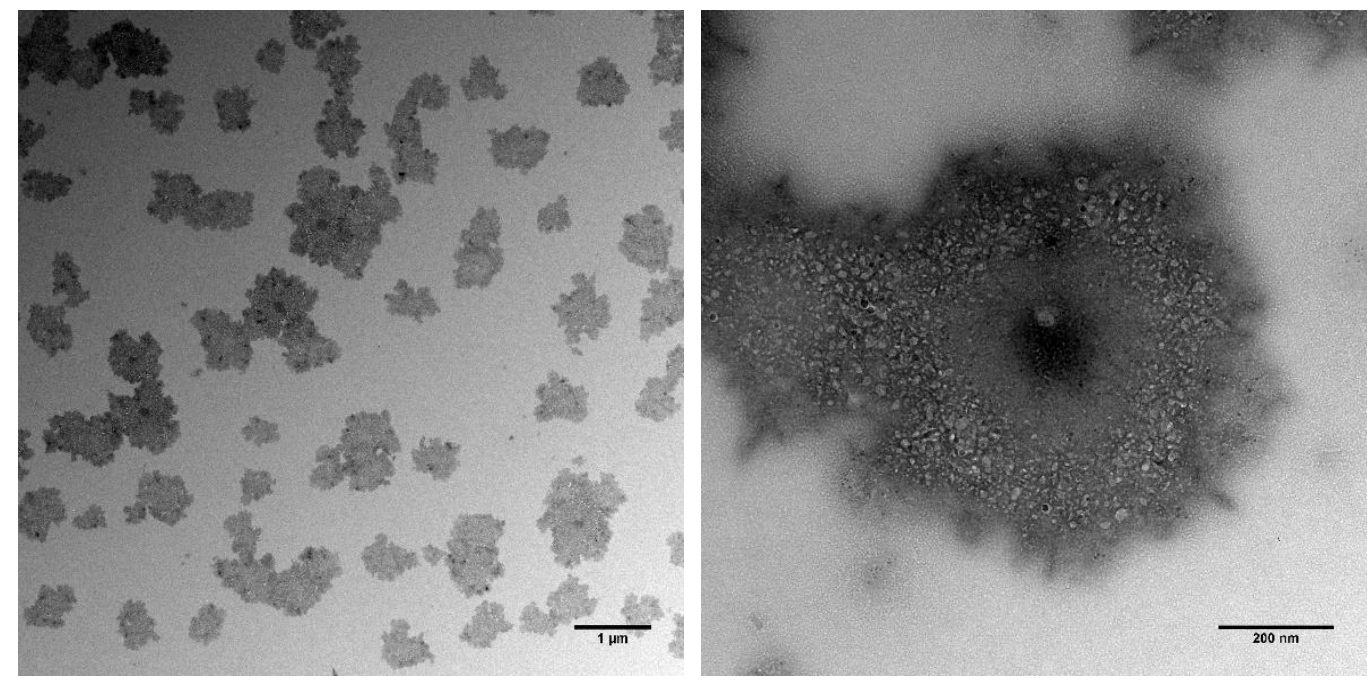

Figure 5. HRTEM micrographs of (a) surfactant micelles $(0.2 \mathrm{wt} \% n$-Dodecyl $\beta$-D-maltoside in brine), and (b) 0/W microemulsions extracted from the diluted rag layer between NAPL 1 and brine 


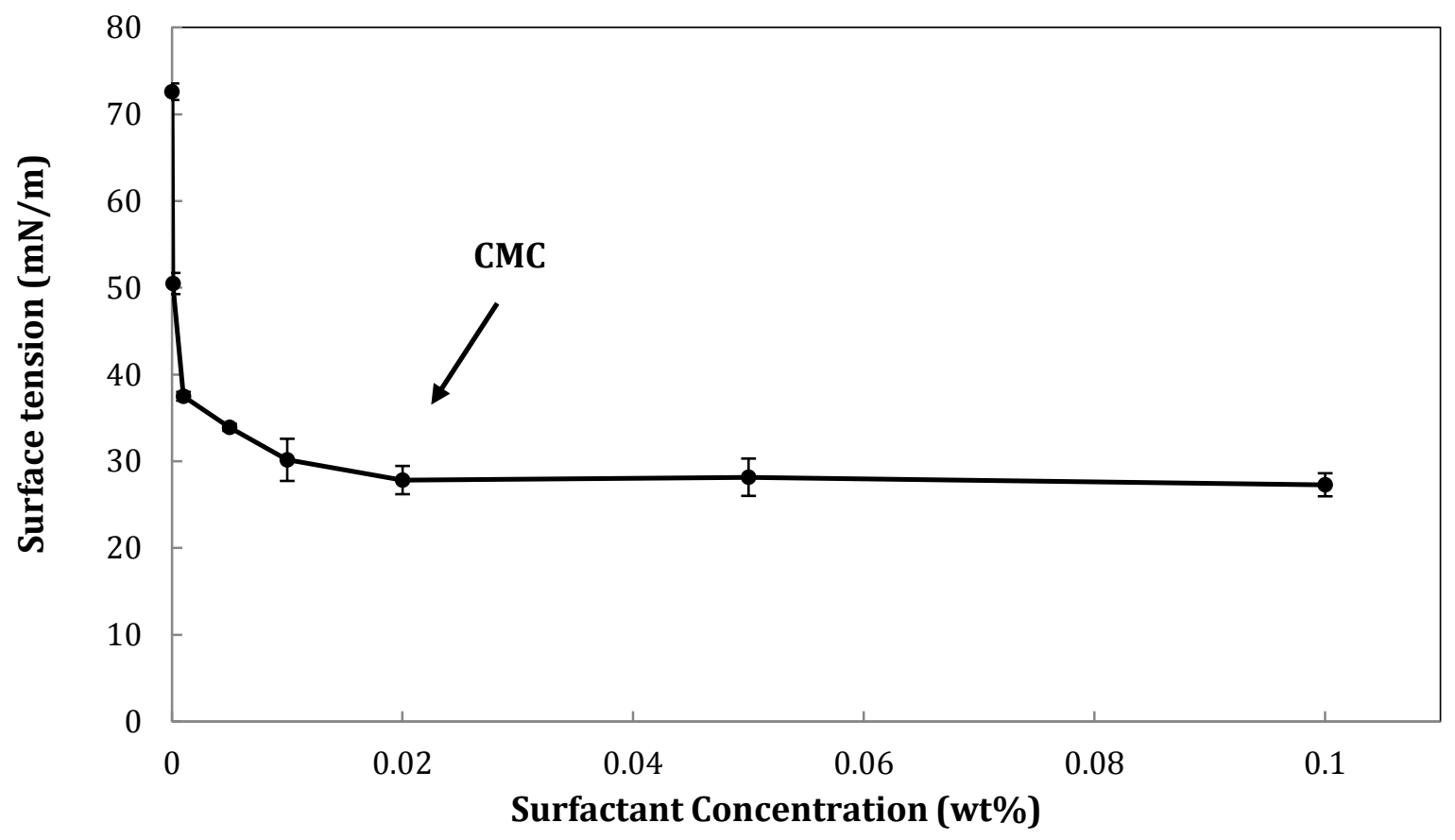

Figure 6. Surface tension of brine versus surfactant concentration

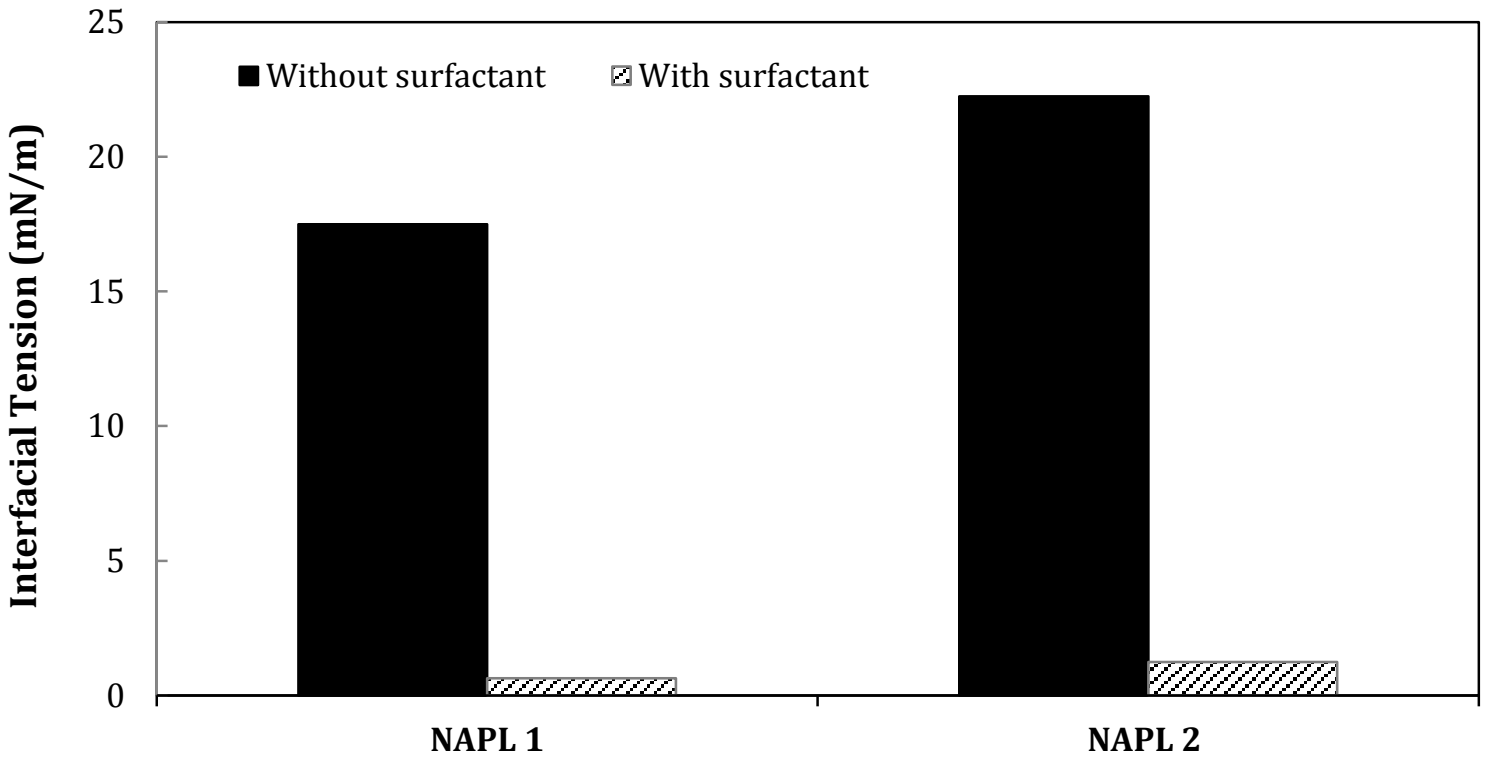

Figure 7. Effect of surfactant on the interfacial tension between NAPL and brine 


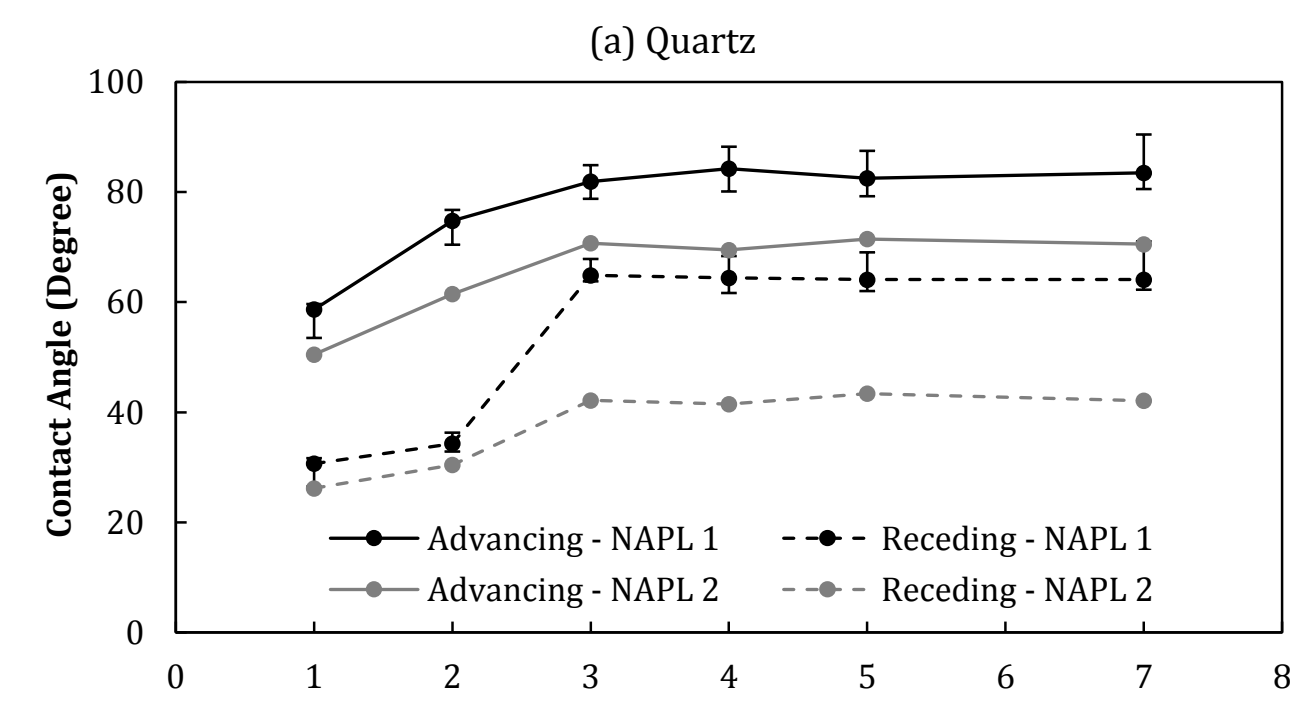

(b) Feldspar

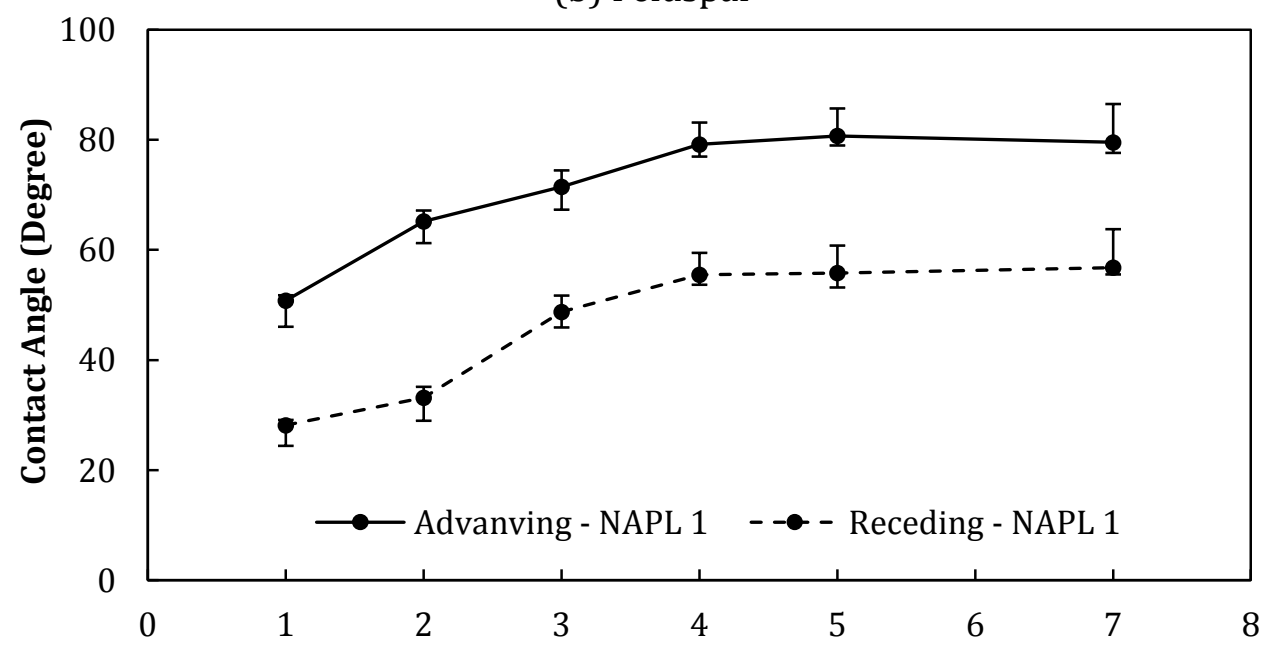

(c) Calcite

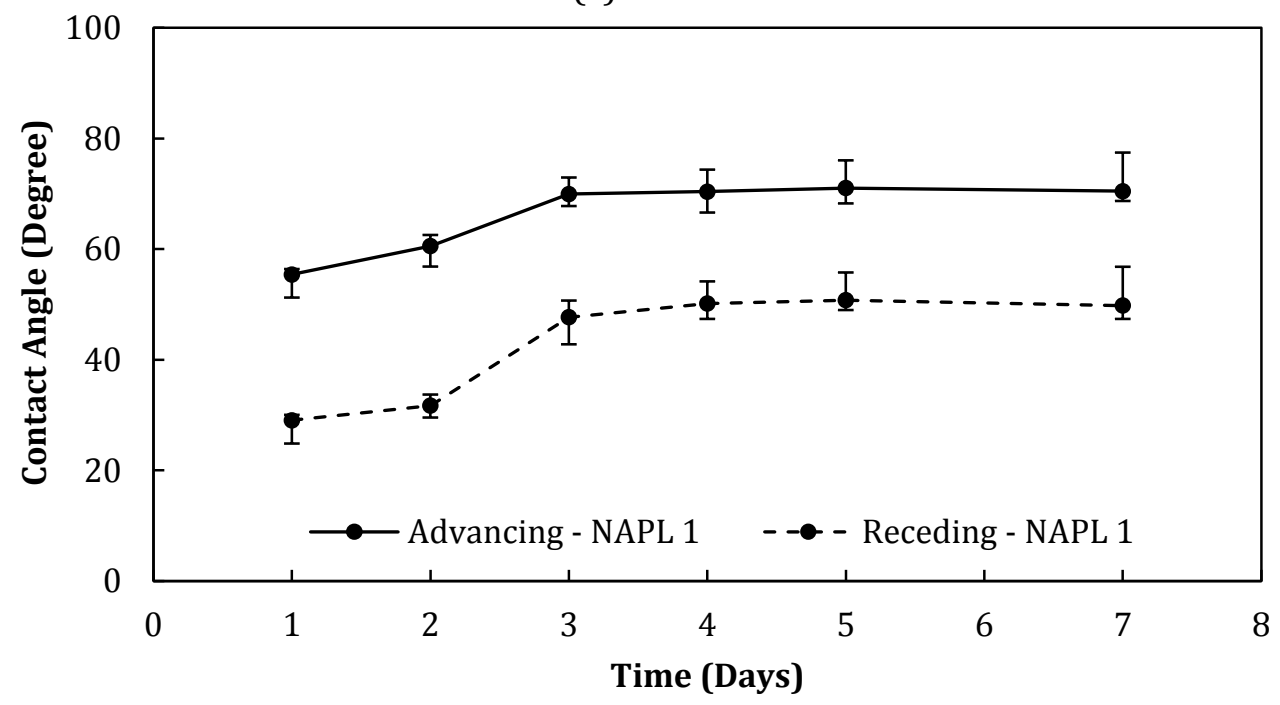

Figure 8. Effect of aging time on the contact angle of brine on NAPL-contaminated minerals 


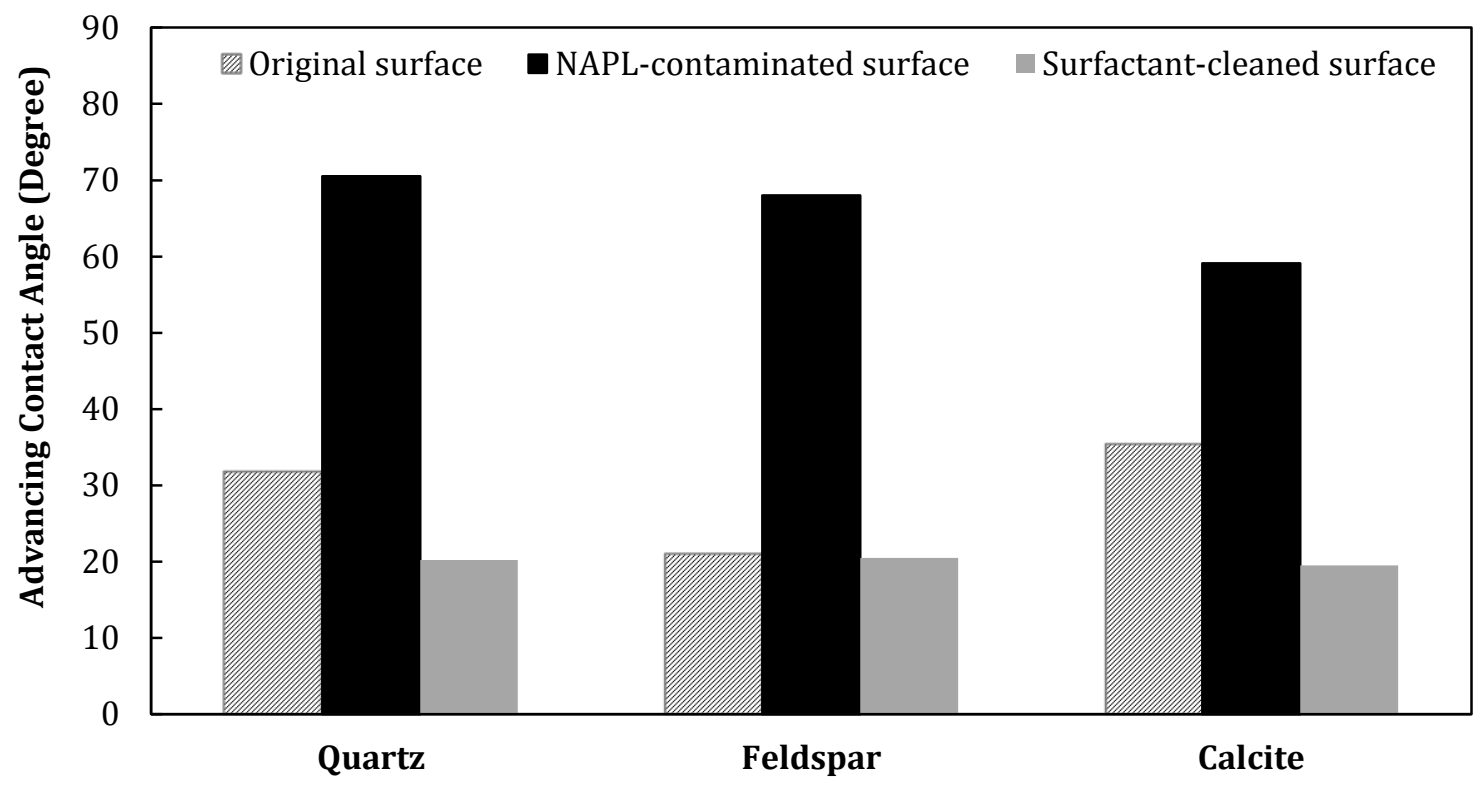

Figure 9. Effect of surfactant on advancing contact angle of brine on NAPL 2-contaminated minerals 
(a) 3 days aging

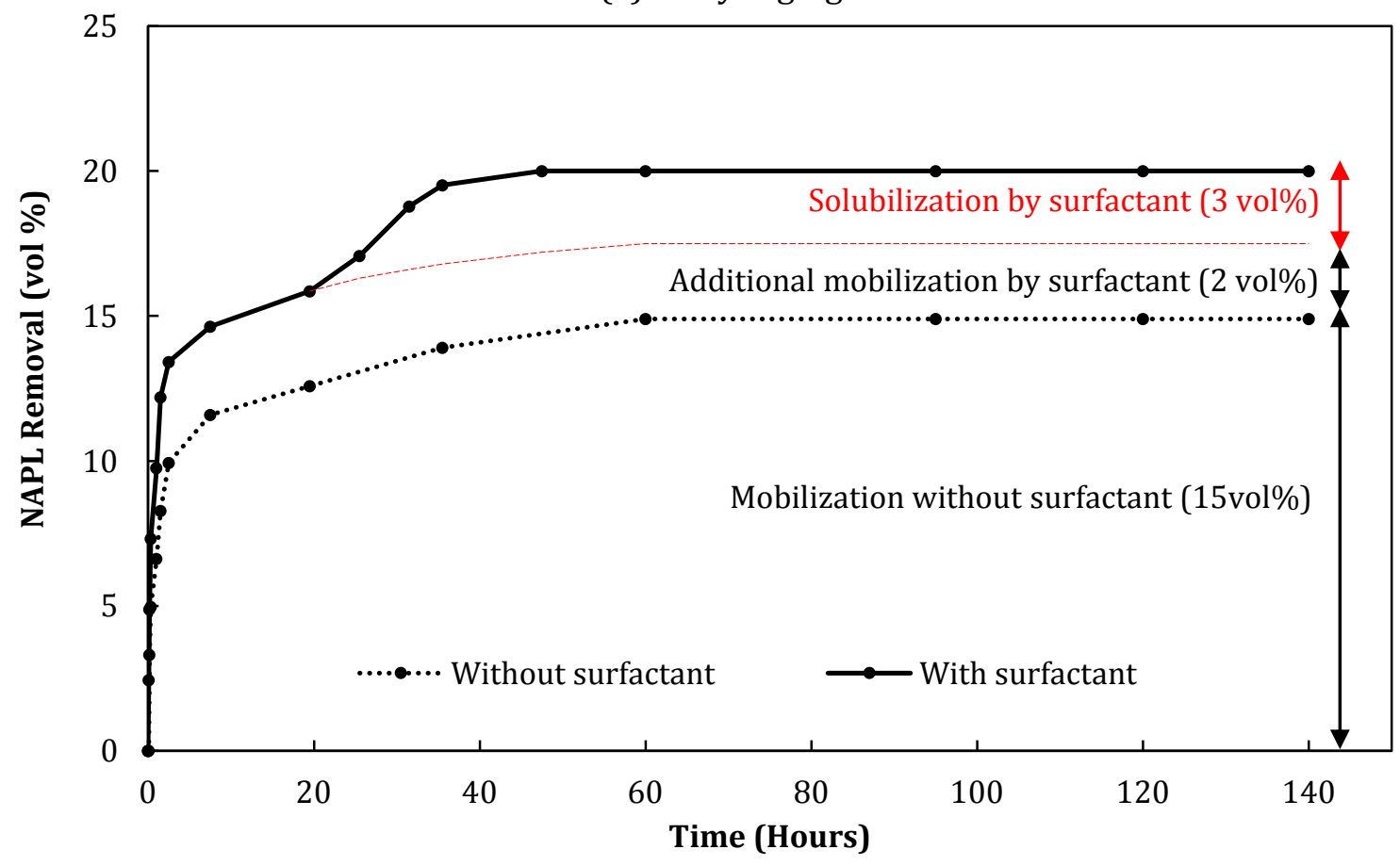

(b) 10 days aging

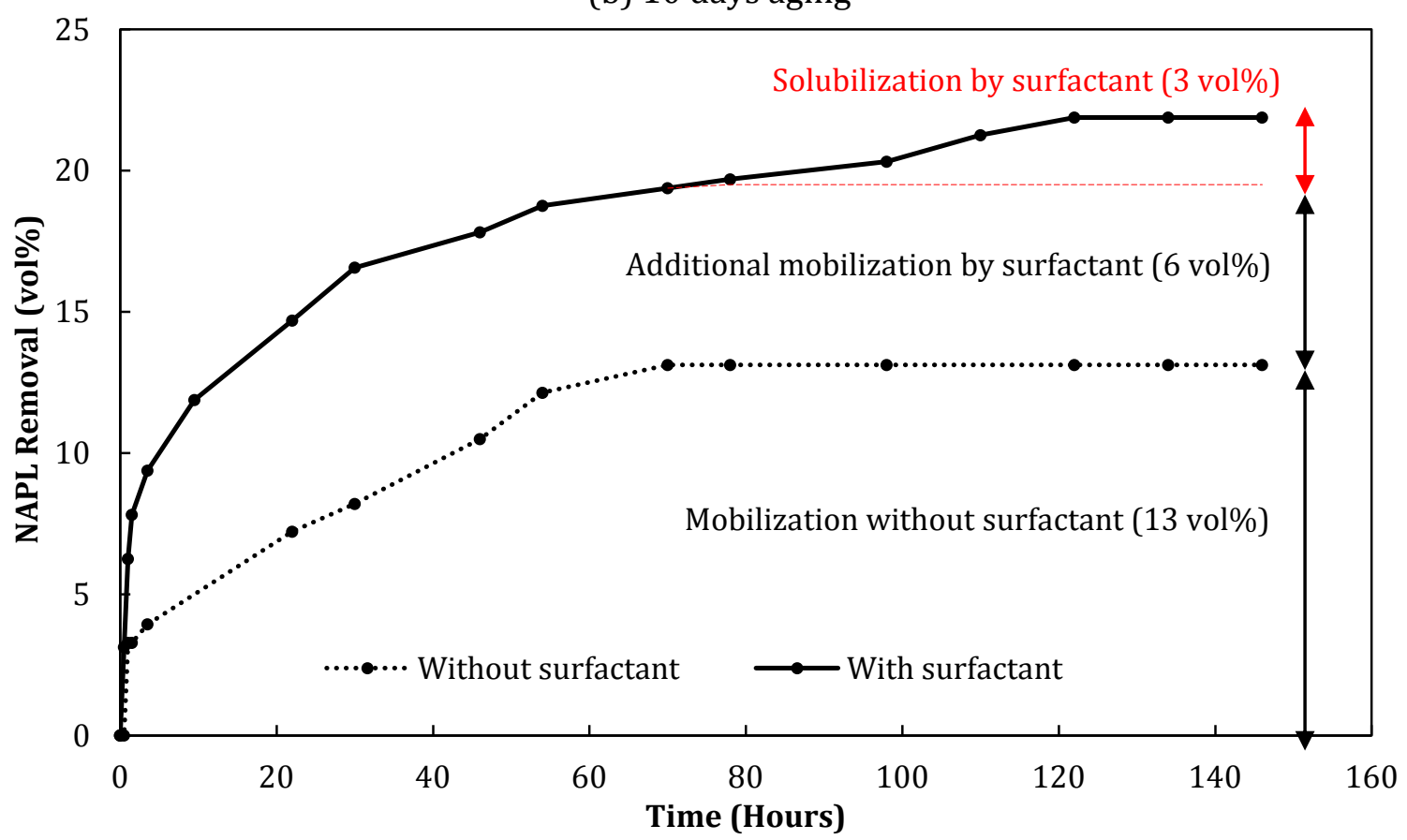

Figure 10. Effect of surfactant-in-brine on NAPL removal from Arkose core samples containing 50 wt $\%$ water and 50 wt\% NAPL 2: (a) 3 days aging, (d) 10 days aging. 


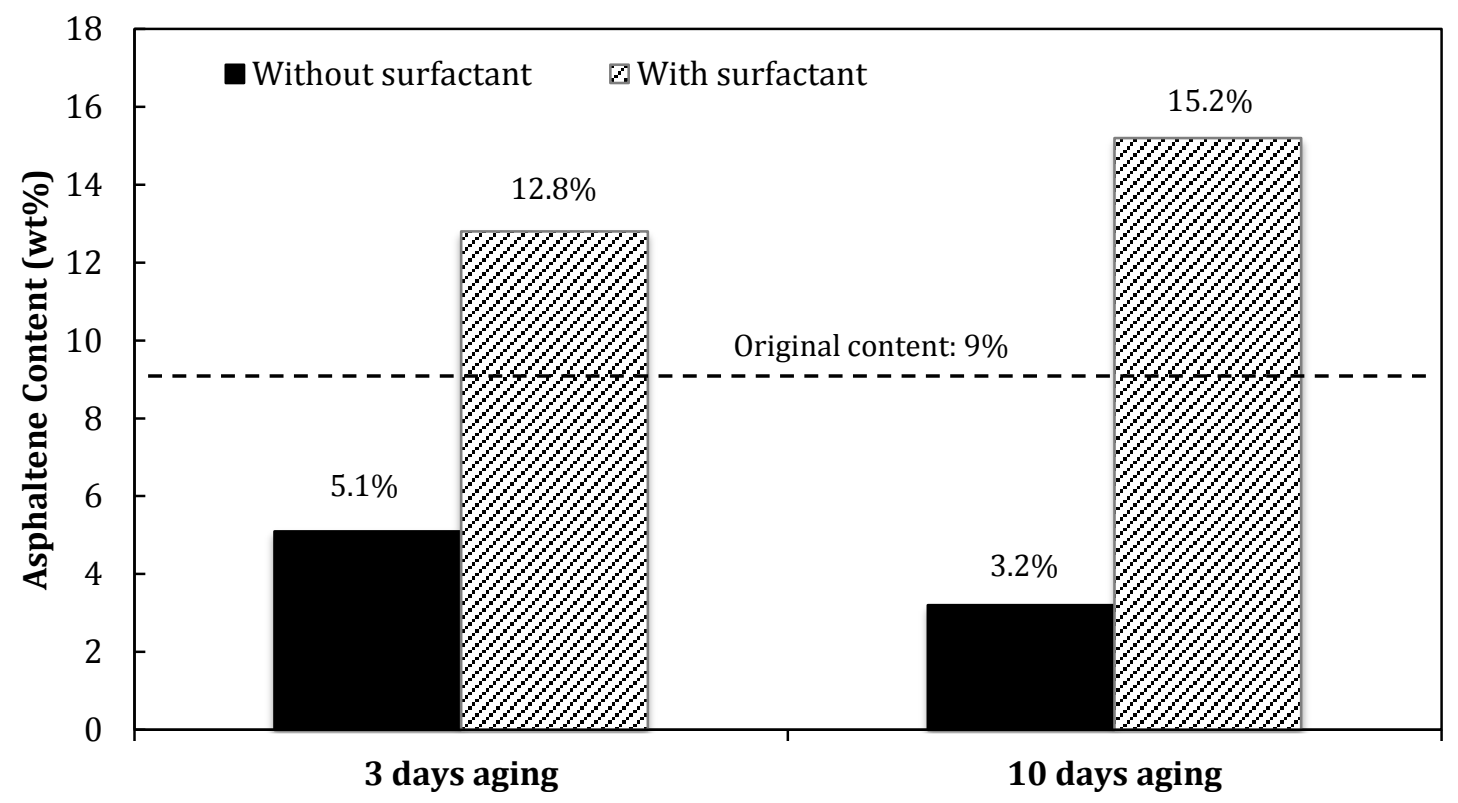

Figure 11. Asphaltene content in NAPL 2 produced from spontaneous imbibition of Arkose cores aged in NAPL for (a) 3 days, and (b) 10 days. 
(a)

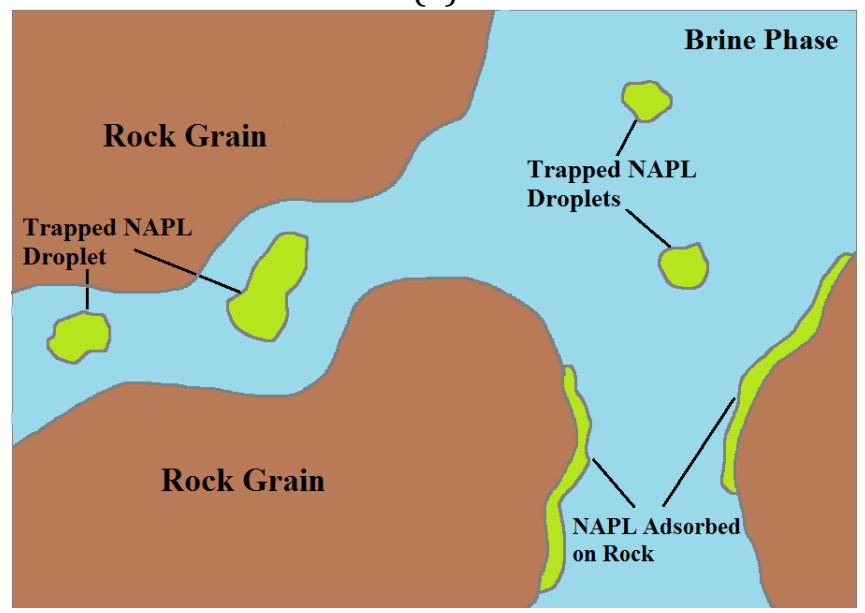

(b)

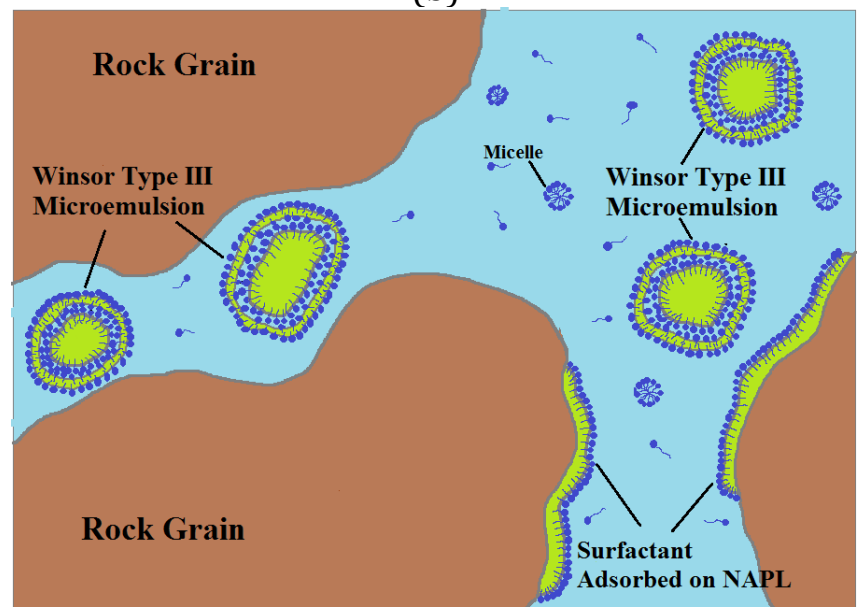

(c)

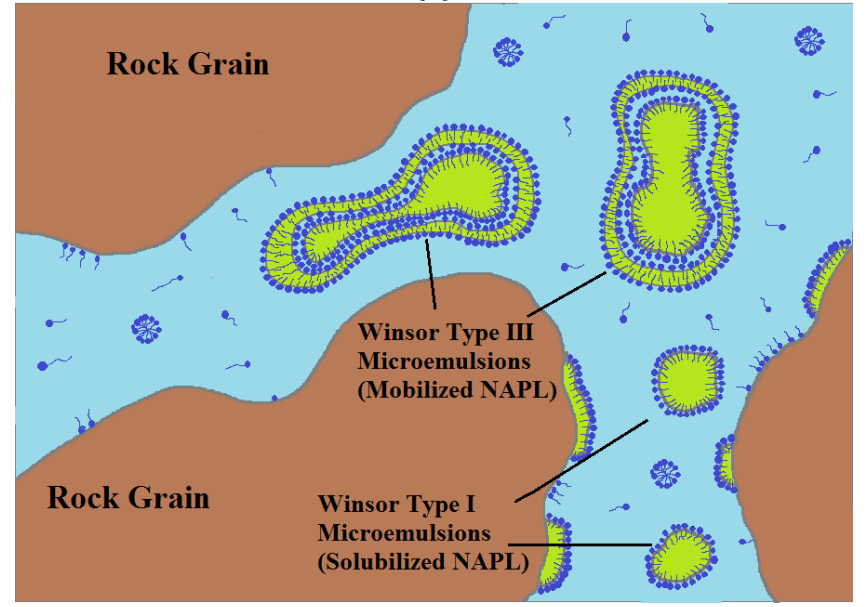

Figure 12. Proccess of NAPL removal from contaminated aquifer: (a) Trapped and adsorbed NAPL, (b) Mobilization of NAPL, (c) Mobilization and micellar solubilization of NAPL 